\title{
RESENHA À OBRA DIREITO DE ARREPENDIMENTO NOS CONTRATOS CIVIS: A PROTEÇÃO DA HIPERVULNERABILIDADE NO DIREITO CIVIL-CONSTITUCIONAL, DE SANTIAGO, MARIA CRISTINA. RIO DE JANEIRO: PROCESSO, 2021
}

\begin{abstract}
Adriano Marteleto Godinho
Professor adjunto da Universidade Federal da Paraíba. Professor do Programa de Pós-Graduação (Mestrado e Doutorado) da UFPB. Pós-Doutorando em Direito Civil pela Universidade de Coimbra. Doutor em Ciências Jurídicas pela Universidade de Lisboa. Mestre em Direito Civil pela Universidade Federal de Minas Gerais. Membro fundador do Instituto Brasileiro de Estudos de Responsabilidade Civil (Iberc) e do Instituto de Direito Civil-Constitucional (IDCC).
\end{abstract}

Durante os séculos XVIII e XIX, o contrato, assim como praticamente toda a construção jurídica, ancorou-se nas premissas da liberdade dos indivíduos e do voluntarismo, isto é, da prevalência da autonomia da vontade. Situando-se o querer individual como o ponto fulcral do direito, natural que houvesse o afastamento do Estado do campo das relações privadas, prevalecendo, portanto, o pleno liberalismo, assoberbando-se o vínculo jurídico oriundo da manifestação volitiva dos particulares sobre quaisquer outros interesses, pouco importando que eventuais injustiças decorressem da atribuição dessa ampla e livre iniciativa aos indivíduos.

Tal concepção atingiu seu ápice no decorrer do século XIX, período em que restou consagrada nas legislações civis, notadamente no Código Napoleão, editado na França, em 1804. 0 pensamento então vigorante resumia-se na clássica sentença "laissez faire, laissez passer, le monde va de lui même".

A autonomia da vontade, no sentido que Ihe conferia a ideologia oitocentista, conferia às pessoas a livre perspectiva de determinação da forma como iriam constituir suas relações de cunho privado. Traduzia-se, em síntese, na plena liberdade de os indivíduos regularem, por meio da concretização dos contratos, as suas próprias conveniências. O princípio, portanto, representou um corolário do liberalismo, que norteava as transações convencionadas entre os particulares, 
permitindo que estes contraíssem direitos e obrigações desmedidamente, da maneira que lhes parecesse mais adequada.

A fórmula empregada por Fouillée, "qui dit contractuel, dit juste", espelhava precisamente os ideais do mais puro liberalismo negocial. Afirmava-se, então, que a justiça contratual era automaticamente assegurada, simplesmente pelo fato de o conteúdo do contrato ter sido livremente estipulado pelas partes. A liberdade de contratar e a igualdade formal dos negociantes, esta correspondente ao pressuposto do idêntico tratamento de todos perante os ditames da lei, eram os pilares fundamentais sobre os quais se assentava a teoria dos contratos.

Todo esse panorama ensejou o nascedouro do princípio da força obrigatória dos contratos, traduzido na afamada máxima pacta sunt servanda, a apregoar que o contrato faz lei entre as partes. A completa abnegação da noção de um mínimo equilíbrio das prestações caracterizava um panorama incompatível com a consagração de institutos jurídicos que, a exemplo do direito de arrependimento - tema central da obra em apreço -, encontram fundamento em uma ideia de promoção da justiça contratual.

As imperiosas modificações na teoria dos negócios jurídicos ganharam terreno na própria conceituação dos contratos, originariamente considerados instrumentos da plena realização da vontade livre dos indivíduos. Uma avença, em sua caracterização hodierna, não mais poderá ser considerada pelo prisma individualista da estrita serventia aos propósitos egoístas dos contratantes, mas no sentido de utilidade para toda a coletividade. Essa verdadeira socialização dos contratos, expressamente reconhecida nos textos das legislações mais modernas, revela-se como uma das mais nítidas facetas de todo um processo de humanização do direito, tão bem explicitado na obra objeto desta resenha.

A moderna concepção dos contratos aponta para o declínio do quadro esquemático característico da filosofia liberal, preponderante nas primeiras codificações civis, inclusive no Código Civil brasileiro de 1916. Inaugura-se uma nova era da teoria dos contratos, claramente mais altruísta, solidária e condizente com a diretriz inafastável da socialidade, e é sobre estas bases que se acomodam os ricos argumentos empregados pela autora, conforme se depreende de sua sensivel compreensão sobre o tema, em trecho extraído da obra resenhada:

A funcionalização das categorias jurídicas de direito privado traz consigo a marca da superação dos interesses individuais em benefício da coletividade. Posteriormente, reforçando também esse perfil solidarista surgem os microssistemas protetivos daqueles que constituíam a massa amorfa da sociedade, também, reconhecidos pela vulnerabilidade que lhes é imanente, passam a ser tutelados em suas individualidades, como ocorreu com o consumidor no Código de 
Defesa do Consumidor (Lei n. 8070/1990); a criança e o adolescente no Estatuto da Criança e do Adolescente (Lei n. 8.060/1990); o idoso no Estatuto do Idoso (Lei n. 10.741/2003); o locatário, através da Lei de Locação (Lei n. 8.245/1991); a pessoa portadora de necessidades especiais, através do Estatuto da Pessoa com Deficiência (Lei n. 13.146/2015), dentre outros exemplos. ${ }^{1}$

A moderna acepção dos contratos constata a necessidade de se estabelecerem limites concretos à autonomia da vontade, em contraposição à conceituação clássica do princípio, outrora praticamente absoluto e irrestrito. A liberdade contratual passa, portanto, a ser encarada sob enfoque diverso: a atual conjuntura exige a intervenção do poder do Estado no âmbito das relações privadas, com o intuito de instituir normas mínimas, reguladoras da autonomia dos particulares, originando-se, então, o fenômeno a que se convencionou designar de dirigismo contratual, muito marcante em microssistemas jurídicos como o Código de Defesa do Consumidor, no Estatuto da Pessoa com Deficiência e em outros diplomas referidos pela autora. Esse intervencionismo simboliza uma reação natural aos exageros oriundos da aplicação do princípio da autonomia da vontade, e seus objetivos, embora favoráveis à parte (hiper)vulnerável, não se dirigem a conceder-Ihe puros privilégios, em prejuízo do outro contratante; ao contrário, o legislador intervém para estabelecer uma desigualdade de tratamento que visa, em última instância, a alcançar um patamar de mínimo equilíbrio contratual, condizente com a principiologia vigorante, fortemente alicerçada nos princípios da boa-fé e da função social dos contratos e no equilíbrio material das obrigações.

Verifica-se, então, que a força obrigatória dos contratos não mais se aprecia à luz de um dever moral de manter a palavra empenhada, mas sob o aspecto de realização do bem comum e de sua finalidade social. 0 tradicional princípio do pacta sunt servanda, que determina às partes o cumprimento dos seus encargos em estrita conformidade com o conteúdo da avença, e que constitui um dos desdobramentos do princípio da autonomia da vontade, flexibiliza-se em função da finalidade social buscada pelos contratos. Já não mais se tolera que a simples existência de um pacto entre as partes represente a obrigatoriedade irrecusável do cumprimento das cláusulas estabelecidas, mormente quando estas se afastem da razoabilidade que deve nortear toda e qualquer relação jurídica.

Neste cenário de humanização do direito civil, surge a fantástica obra objeto desta resenha, intitulada Direito de arrependimento nos contratos civis: a proteção da hipervulnerabilidade no direito civil-constitucional, que resulta do notável

SANTIAGO, Maria Cristina. Direito de arrependimento nos contratos civis: a proteção da hipervulnerabilidade no direito civil-constitucional. Rio de Janeiro: Processo, 2021. p. 181. 
trabalho de pesquisa desenvolvido pela autora ao longo de anos dedicados ao estudo do tema. Trata-se de uma obra que se propõe a revolucionar a compreensão acerca dos modos de extinção dos contratos, em que a autora propõe a ruptura do pensamento clássico do direito civil, ancorado na premissa da isonomia e do equilíbrio entre os contratantes, em prol da defesa dos direitos dos hipervulneráveis, isto é, das pessoas que contratam em notória condição de debilidade.

Trata-se de uma perspectiva humanizada do contrato, a descartar a lógica de considerar os pactuantes a partir da perspectiva do "homem médio" para, enfim, cuidar da pessoa real, do indivíduo que contrata, cercado de todas as suas fragilidades e das vicissitudes de cada caso concreto. Assim, a autora propõe a ruptura com o tradicional paradigma do "sujeito de direito" incógnito, dando-se lugar à tutela do ser humano em concreto. Eis o grande contributo da obra: o paradigma da humanização do direito civil encontra porto seguro nas linhas tracejadas pela autora e é mote de todo o desenvolvimento do texto.

No segundo capítulo, superada a introdução, a obra toca a proteção dos hipervulneráveis em contratos de consumo, eis que, no âmbito dos negócios consumeristas, surge como necessário pressuposto o reconhecimento (supostamente ausente, à partida, nos contratos civis) da vulnerabilidade própria do consumidor, o que contribui sobremaneira para a realização do primado da justiça contratual. Com efeito, destaca a autora a relevância da emergência do Código de Defesa do Consumidor como instrumento paradigmático de tutela dos consumidores e da consagração a premissa do equilíbrio negocial.

Adiante, no terceiro capítulo, a autora demonstra com maestria a evolução dos paradigmas contratuais, inaugurando-se neste domínio um cenário pautado pela consagração dos princípios da função social, da boa-fé e do equilíbrio material das obrigações. Dá-se, neste cenário, conforme já destacado, a passagem de um modelo voluntarista e individualista dos contratos rumo a uma ideologia solidarista. Assim é que a autora assinala que "[...] na seara do contrato a justiça comutativa corporifica-se na busca do equilíbrio material entre as partes, impedindo que o contratante mais frágil assuma obrigações desproporcionais dentro da economia globalizada". ${ }^{2}$

Estas são as bases para a construção dos dois derradeiros capítulos da obra, que problematizam a lógica da igualdade e da liberdade contratual para atingir, enfim, o seu ápice: a brava defesa da ideia de que o direito de arrependimento, instrumento de amplo alcance no âmbito dos contratos de consumo, deva também se estender para os domínios dos contratos civis, desde que uma das partes

SANTIAGO, Maria Cristina. Direito de arrependimento nos contratos civis: a proteção da hipervulnerabilidade no direito civil-constitucional. Rio de Janeiro: Processo, 2021. p. 127. 
ostente a condição de hipervulnerável. Para sustentar sua proposta, Maria Cristina Santiago vale-se de robustos argumentos, que, nesta ordem de ideias: i) tocam a teoria do diálogo das fontes, a defender uma coerência sistemática entre os diplomas jurídicos do direito privado, nomeadamente o Código Civil e o Código de Defesa do Consumidor, muito particularmente; ii) apregoam a defesa dos vulneráveis nos contratos civis, o que se prova, em especial, pela consagração do instituto da lesão no art. 157 do Código Civil de 2002, a permitir ao contratante em situação de debilidade (seja por inexperiência ou em virtude de premente necessidade de contratar) reclamar a revisão e eventualmente até mesmo a anulação de todo e qualquer contrato em que se verifique a caracterização de uma desproporção manifesta entre as prestações assumidas de parte a parte, isto é, de um cenário de flagrante disparidade negocial, a contrariar radicalmente o princípio do equilíbrio material das obrigações; iii) por fim, alcançam o ponto central do debate proposto na obra: demonstrar de que modo o direito de arrependimento, explicitamente consagrado no texto do Código de Defesa do Consumidor, pode também ser invocado no âmbito dos contratos civis. Para que tal se dê, é fundamental a verificação da circunstância de hipervulnerabilidade de uma das partes, independentemente de a contratação ocorrer fora do estabelecimento comercial, vale dizer, inclusive nos casos em que a negociação se concretiza em caráter presencial.

A hipervulnerabilidade de um dos contratantes é eleita, pois, como o pressuposto por excelência da incidência do direito de arrependimento nos contratos civis. Para justificar sua corajosa tese, a autora argumenta que, mesmo nos contratos de consumo, em relação aos quais há expresso reconhecimento em lei de um direito de arrependimento, é de se exigir uma vulnerabilidade aumentada do consumidor, que contrata sem ter acesso à experiência sensorial na avaliação do produto adquirido; assim, para que o instrumento do arrependimento seja invocado legitimamente como direito extintivo dos contratos, caberia a demonstração de que a parte a suscitar tal direito em seu proveito se acha em situação de vulnerabilidade agravada. Como consequência, caberia dizer, nas palavras da própria autora:

[...] quando o sujeito contratante fosse hipervulnerável, o contrato somente estaria perfeito e acabado, após a fluência do prazo de arrependimento. [...] Seria tão-somente o acolhimento de mais um risco, próprio das atividades negociais, consubstanciadas no reconhecimento da possibilidade de exercício do direito potestativo de arrependimento nos negócios jurídicos firmados por pessoas hipervulneráveis, independentemente de se tratar de um contrato de consumo ou de um contrato civil. $^{3}$

3 SANTIAGO, Maria Cristina. Direito de arrependimento nos contratos civis: a proteção da hipervulnerabilidade no direito civil-constitucional. Rio de Janeiro: Processo, 2021. 
Em tempos de manifesta defesa de um extremado liberalismo econômico - a representar, na seara negocial, um potencial enfraquecimento dos princípios contemporâneos norteadores dos contratos em prol da suposta concessão de maiores espaços de autonomia, tal como outrora -, a obra dirige-se ousadamente na direção oposta, a fim de proteger os interesses dos contratantes mais débeis e de consagrar o contrato como fonte de troca justa e equilibrada de interesses e riquezas.

O enfrentamento dos temas é irretocável, cumprindo registrar que, em tempos de publicações de questionável mérito no mercado editorial, particularmente na seara jurídica, a obra resenhada apresenta qualificada investigação de uma temática árdua e melindrosa e fomenta discussões calcadas em sólidos alicerces metodológicos, o que coopera para a afirmação das bases da ciência jurídica, constantemente em (des)construção.

Esta breve resenha não faz (e sequer ensaia a mera tentativa de fazer) jus à obra, que deve ser lida e compreendida em sua inteireza. O livro contempla todas as qualidades típicas das melhores criações no âmbito das letras jurídicas e, por isso, passa a ser necessária referência de estudo.

Informação bibliográfica deste texto, conforme a NBR 6023:2018 da Associação Brasileira de Normas Técnicas (ABNT):

SANTIAGO, Maria Cristina. Direito de arrependimento nos contratos civis: a proteção da hipervulnerabilidade no direito civil-constitucional. Resenha de: GODINHO, Adriano Marteleto. Revista Brasileira de Direito Civil - RBDCivil, Belo Horizonte, v. 28, p. 293-298, abr./jun. 2021. 